\title{
Serial carotid MRI identifies rupture of a vulnerable plaque resulting in amaurosis fugax
}

Figure 1 Baseline high-resolution carotid MRI after cryptogenic stroke

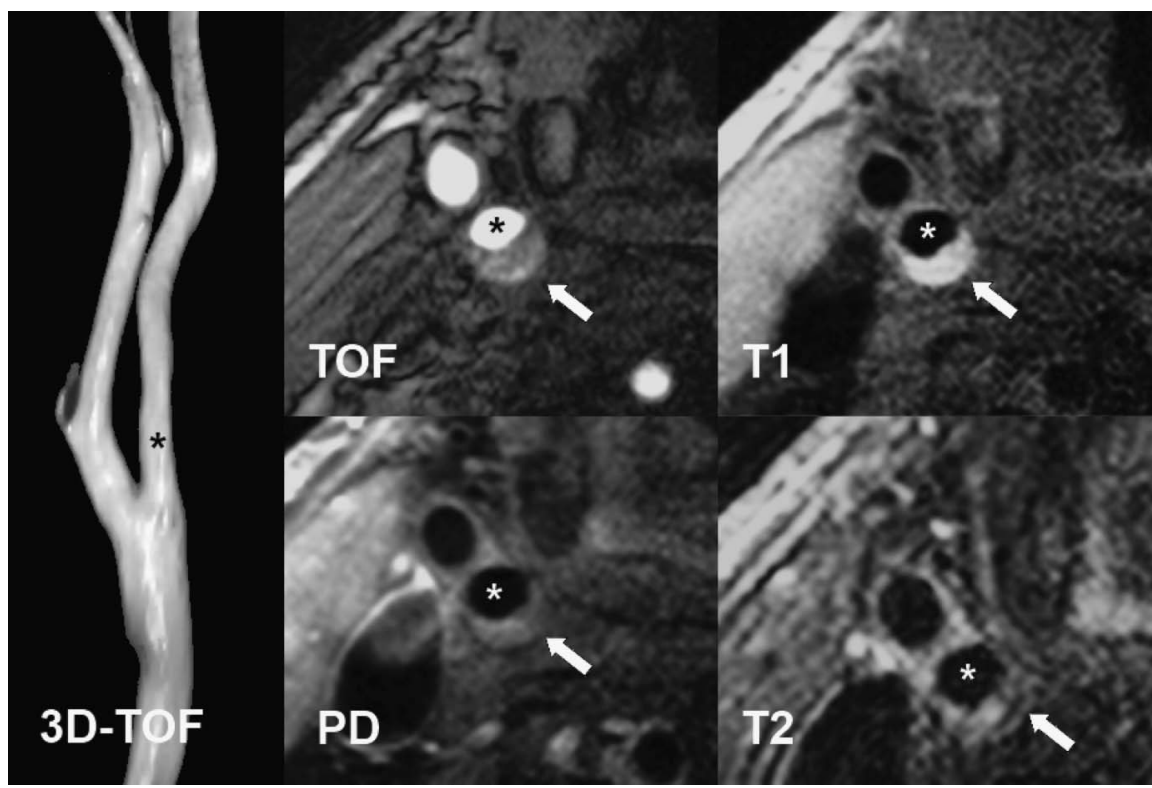

Baseline carotid MRI demonstrating a complicated American Heart Association type-VI plaque of the right internal carotid artery (*). High signal on time-of-flight (TOF) and T1-weighted images (arrow) corresponding to intraplaque hemorrhage within a large lipid/necrotic core. PD = proton density; 3D = 3-dimensional.

A 66-year-old man with cryptogenic ischemic stroke and multiple acute ischemic lesions in the right middle cerebral artery territory was enrolled in the CAPIAS trial (Carotid Plaque Imaging in Acute Stroke; NCT01284933). Baseline carotid MRI demonstrated a right-sided nonstenotic American Heart Association type-VI plaque with a large lipid/necrotic core and intraplaque hemorrhage (figure 1). Eleven months later, the patient presented again after an episode of right eye amaurosis fugax. Repeat carotid MRI revealed a new ulceration on the right side with large parts of the former lipid/necrotic core missing (figure 2). We hypothesize that plaque rupture had caused embolization into the right retinal artery.

Figure 2 Repeat carotid MRI after an episode of amaurosis fugax (11 months later)

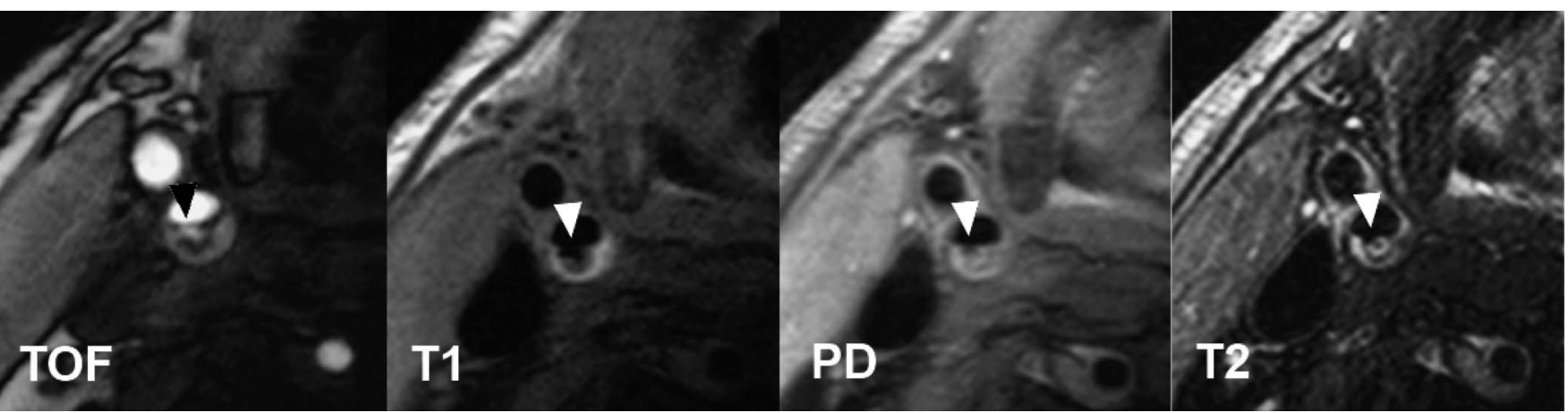

At repeat $\mathrm{MRI}$, this plaque showed profound superficial irregularities, with a new ulceration and parts of the former lipid/necrotic core missing (arrowhead). $\mathrm{PD}=$ proton density; TOF $=$ time of flight. 
From the Institute for Clinical Radiology (F.S., M.B., C.C., J.G., A.H., K.N., T.S.), Institute for Stroke and Dementia Research (A.B.K., C.O., M.D.), and Department of Neurology (C.O., M.D.), Ludwig-Maximilians-University Hospital Munich; and Department of Neurology (H.P.), Technical University Munich, Germany.

Author contributions: Florian Schwarz: drafting/revising the manuscript, study concept or design, analysis or interpretation of data, contribution of vital reagents/tools/patients, acquisition of data. Anna Bayer-Karpinska: drafting/revising the manuscript, study concept or design, analysis or interpretation of data, acquisition of data. Holger Poppert: drafting/revising the manuscript. Martin Buchholz: drafting/revising the manuscript, analysis or interpretation of data, acquisition of data. Clemens Cyran: drafting/revising the manuscript, study concept or design, analysis or interpretation of data, acquisition of data, study supervision. Jochen Grimm: drafting/ revising the manuscript, analysis or interpretation of data, acquisition of data. Andreas Helck: analysis or interpretation of data, acquisition of data. Konstantin Nikolaou: drafting/revising the manuscript, study concept or design, study supervision. Christian Opherk: analysis or interpretation of data, acquisition of data, study supervision. Martin Dichgans: drafting/revising the manuscript, analysis or interpretation of data, acquisition of data. Tobias Saam: drafting/revising the manuscript, study concept or design, analysis or interpretation of data, acquisition of data, study supervision.

Study funding: No targeted funding reported.

Disclosure: F. Schwarz and A. Bayer-Karpinska report no disclosures. H. Poppert has received speaker honoraria from Bayer Schering Pharma, Roche, Boehringer Ingelheim, ev3, and Novartis and receives research support from BMWi and Deutsche Stiftung Neurologie. M. Buchholz, C. Cyran, J. Grimm, and A. Helck report no disclosures. K. Nikolaou has served on a scientific advisory board for Bayer Schering Pharma; serves as Cardiac Section Editor for European Radiology; receives royalties from the publication of Multislice CT, 3rd edition (Springer, 2005); and serves on speakers' bureaus for and has received speaker honoraria from Bayer Schering Pharma, Bracco, and Siemens Medical Solutions. C. Opherk receives research support from the Deutsche Forschungsgemeinschaft and the Dr. Werner Jackstädt Foundation; has served on scientific advisory boards for Boehringer-Ingelheim and Bristol-Myers Squibb; and has received speaker honoraria from Boehringer-Ingelheim. M. Dichgans receives research support from BMB, NGFNPlus, Wellcome Trust, and the Foundation for Vascular Dementia Research. T. Saam receives research support from Bayer Schering Pharma and Diamed Medizintechnik. Go to Neurology.org for full disclosures.

Correspondence to Dr. Saam: Tobias.Saam@med.lmu.de

\section{NeuroImages Are Free at www.neurology.org!}

All Neurology ${ }^{\circledR}$ NeuroImages can now be freely accessed on the Neurology Web site. See them at www.neurology.org, where you can also sign up for journal email alerts and check out other online features, including the Resident \& Fellow section, Neurology: Clinical Practice, and the weekly Neurology Podcasts. 


\section{Neurology}

\section{Serial carotid MRI identifies rupture of a vulnerable plaque resulting in amaurosis fugax \\ Florian Schwarz, Anna Bayer-Karpinska, Holger Poppert, et al.}

Neurology 2013;80;1171-1172

DOI 10.1212/WNL.0b013e31828869ad

This information is current as of March 18, 2013

\section{Updated Information \& Services}

Subspecialty Collections

Permissions \& Licensing

Reprints including high resolution figures, can be found at: http://n.neurology.org/content/80/12/1171.full

This article, along with others on similar topics, appears in the following collection(s):

\section{All Cerebrovascular disease/Stroke}

http://n.neurology.org/cgi/collection/all_cerebrovascular_disease_str oke

Infarction

http://n.neurology.org/cgi/collection/infarction

MRI

http://n.neurology.org/cgi/collection/mri

Information about reproducing this article in parts (figures, tables) or in its entirety can be found online at:

http://www.neurology.org/about/about_the_journal\#permissions

Information about ordering reprints can be found online:

http://n.neurology.org/subscribers/advertise

Neurology ${ }^{\circledR}$ is the official journal of the American Academy of Neurology. Published continuously since 1951, it is now a weekly with 48 issues per year. Copyright (C) 2013 American Academy of Neurology. All rights reserved. Print ISSN: 0028-3878. Online ISSN: 1526-632X.

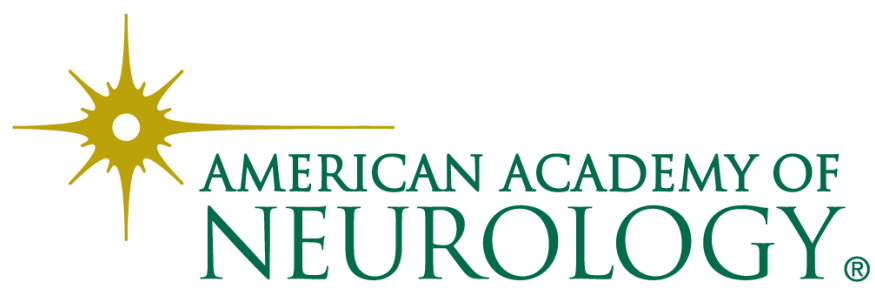

